\title{
BIMBINGAN PENGUATAN MODAL SOSIAL \\ BAGI GENERASI MUDA KELUARGA NELAYAN \\ DI DESA BAJO INDAH KEC. SOROPIA KAB. KONAWE
}

\author{
${ }^{1}$ Muhammad Rusli, 2Muhammad Arsyad, 3Juhaepa, \\ ${ }^{4}$ Ratna Supiyah, ${ }^{5}$ Sarpin, ${ }^{6}$ Desi Fitriyanti \\ 123456Fakultas IImu Sosial dan Ilmu Politik Universitas Halu Oleo \\ Jl. HEA Mokodompit No.1 Kampus Bumi Tridharma Anduonohu, Kendari 93232
}

\section{RINGKASAN}

Pembimbingan penguatan modal sosial generasi muda Bajo dilatarbelakangi pemikiran bahwa etnis Bajo yang dikenal sebagai nelayan tangguh dan unik sekaligus memberi sumbangsih terhadap ketersediaan ikan untuk kebutuhan pokok masyarakat di mana eksistensinya sangat ditentukan oleh modal sosialnya. Oleh karena modal sosial perlu diwarisi dan diperkuat oleh generasi Bajo itu sendiri. Melalui ceramah dan diskusi dalam kelompok kecil diperoleh kesimpulan bahwa hampir semua generasi muda yang dibimbing telah menyadari pentingnya modal sosialnya dan perlu mewarisi modal sosial, seperti kebanggaan untuk menjadi nelayan, trust (saling percaya), saling membantu dan kerja sama serta etos kerja yang selama ini menjadi ciri masyarakat Bajo. Umumnya mereka bertekad untuk menjaga modal sosial yang disebutkan di atas karena melihat manfaat, baik untuk kesejahteraan keluarganya maupun untuk kepentingan mendukung program wisata dimana budaya Bajo yang unik seperti kemampuan menyelam dan perempuan nelayan Bajo yang dapat melaut menggunakan perahu lepa sendirian dengan hanya menggunakan dayung dan layar menelusuri laut mencari hasil laut.

Kata kunci: bimbingan; penguatan; modal social; generasi muda; nelayan

\section{A. Latar Belakang \\ 1. (Analisis Situasi)}

Bajo dikenal sebagai 'manusia air' karena selain rumahnya yang di atas air, komunitas ini hidup tidak bisa dipisahkan dengan laut dan kehidupannya hampir seluruhnya bersumber dari laut. Pekerjaan sebagai pencari hasil laut yang sangat tangguh sehingga menjadi komunitas yang unik sekaligus memberi sumbangsih terhadap ketersediaan hasil laut untuk kebutuhan pokok masyarakat di samping untuk kehidupan anggota keluarganya. Eksistensi komunitas nelayan ini sangat ditunjang oleh modal sosialnya (Zacot, 2008)

Keunikan dan pentingnya keberadaan komunitas Bajo, khususnya di Desa Bajo Indah terutama karena didukung modal sosial, namun dikuatirkan modal sosial mengalami pergeseran bagi generasi mudanya sementrara modal sosial ini merupakan faktor atau modal utama komunitas Bajo untuk meraih kesejahteraan sosial keluarganya (Rusli, 2014). 


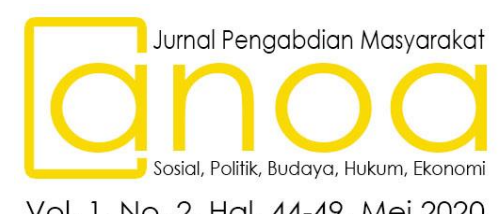

Vol. 1, No. 2, Hal. 44-49, Mei 2020

Modal sosial diantaranya berupa nilai kebanggaan menjadi nelayan, etos kerja, solidaritas, trust, partisipasi dalam kegiatan sosial, dan berbagai nilai sosial lain menurut tokoh masyarakat Bajo dan beberapa orang tua dari kalangan etnis ini dikwatirkan mengalami perubahan pada generasi muda mereka. Di antara ditemukan gejala bahwa sebagian dari anak muda mereka tidak lagi ingin bekerja sebagai nelayan. Generasi muda mereka juga tidak lagi memiliki nilai kerja keras sebagaimana orang tuanya bahkan banyak yang hidup santai tanpa bekerja. Begitu pula modal sosial lain yang berubah yang diduga pengaruh kehidupan modern, baik karena tinggal tidak jauh dari kota maupun karena pergaulan dengan remaja dari etnis lain serta pengaruh dari media sosial atau budaya luar (Rusli, 2018).

Modal sosial komunitas ini mempunyai nilai produktif bahkan nilai unik. Nilai produktifnya berupa hasil laut yang sangat dibutuhkan untuk konsumsi setiap hari oleh banyak orang, bahkan banyak orang yang sangat tergantung kepada ikan untuk kebutuhan setiap hari. Nilai unik "manusia air" merupakan kekayaan budaya bangsa yang menarik sehingga merupakan salah satu budaya asset bangsa. Oleh karena itu perlu dijaga kelestariannya dengan cara bagaimana modal sosial masyarakat maritim ini untuk dapat diwarisi oleh generasi mudanya.

Modal sosial ini merupakan hasil dari konstruksi sosial sehingga dapat dilakukan perlakuan atau rekayasa untuk dapat mempertahankan atau merubahnya melalui pendekatan konstruksi sosial, diantaranya melalui pemeberian informasi dan pengetahuan serta bimbingan kepada kepada generasi muda Bajo dalam melakukan tindakan nyata untuk menjaga eksistensi modal sosialnya.

Berdasarkan latar belakang tersebut di atas dimana ada gejala modal sosial mengalami pergeseran padahal modal sosial mempunyai nilai yang sangat positif baik untuk kesejahateraan sosial keluarga komunitas Bajo sendiri maupun sebagai asset bangsa sehingga diperlukan langkah-langkah bagaimana melestarikan modal sosial ini melalui pewarisan kepada generasi muda komunitas Bajo karena diyakini bahwa modal sosial ini merupakan hasil konstruksi sosial sehingga dapat direkayasa atau dikonstruksi sosial, khususnya melalui bimbingan oleh orang-orang yang mempunyai kompetensi dalam bidang sosiologis tersebut.

\section{B. Metode Pelaksanaan}

\section{Identifikasi Peserta}

Langkah pertama dalam kegiatan bimbingan ini adalah mengenali peserta, terutama tingkat pendidikan, kegiatan sehari-hari, bakat dan cita. Pengenalan ini dilakukan melalui komunikasi langsung dengan yang bersangkutan dan atau melalui orang yang mengenalnya. Tujuan pengenalan ini dalam rangka memahami keberadaanya agar dapat diarahkan sesuai kemampuan komunikasi dan potensi serta cita-citanya.

\section{Perkenalan Pembimbing dan Tujuan Kegiatan}

Setelah mengenal calon bimbingan kemudian pembimbing memperkenalkan diri terutama yang berkaitan dengan kompetensi agar mereka bisa percaya dan menerima arahan pembimbing. Tujuan kegiatan ini juga diperkenalkan agar yakin bahwa tujuan ini untukk kepentingan mereka dan dilakukan secara resmi. 


\section{Materi, Penyampaian dan Diskusi Materi}

Materi meliputi:

- Pengetian Modal Sosial

- Manfaat Modal Sosial Secara Umum

- Manfaat dan Keunggulan Modal Sosial Komunitas Bajo

- Strategi Melestarikan Modal Sosial

- Solusi Mengatasi Masalah secara Umum dan Khusus Generasi Muda Bajo Materi ini disampaikan dengan metode ceramah dan siskusi

\section{Bimbingan Teknis atau Langkah Konkrit Pemanfaatan Modal Sosial}

Bimbingan teknis dilakukan secara kelompok khusus dan individu oleh pembimbing. Bimbingan kelompok khusus adalah bimbingan terhadap peserta yang mempunyai kategori permasalahan sama, baik dalam hal potensi maupun bakat yang sama. Bimbingan ini dengan cara diskusi kelompok (FGD). Bimbingan individu dilakukan untuk mengarahkan secara khusus mengatasi masalah individu.

\section{Evaluasi}

Kegiatan terakhir adalah mengevaluasi perubahan pola pikir dan langkah nyata yang terjadi setelah dilakukan bimbingan.

\section{Hasil Dan Pembahasan}

\section{Analisis Kegiatan}

Kegiatan Pengabdian kepada Masyarakat dalam bentuk pembimbingan penguatan modal sosial yang dilaksanakan di Balai Desa Bajo Indah Kecamatan Soropia Kab. Konawe terdiri dari dua metode kegiatan. Metode pertama penyampaian materi dalam bentuk ceramah pentingnya modal sosial masyarakat Bajo kepada 21 orang pemuda dan pemudi Bajo (10 perempuan dan 11 laki-laki) dan Sekretaris Desa Bajo Indah. Metode kedua pembimbingan dalam kelompok kecil di mana setiap dosen masing-masing menangani empat orang berupa pendalaman penguatan materi sekaligus evaluasi kegiatan pembimbingan. Dalam metode kedua ini dilakukan dengan cara berbincang-bincang dan diskusi tentang pentingnya modal sosial bagi mereka. Dalam perbincangan ini pula dilakukan evaluasi tentang pemahaman dan respon terhadap penguatan modal sosial masyarakat Bajo. Modal sosial yang menjadi materi utama yang diupayakan untuk tetap dipertahankan atau diteruskan kepada generasi mudanya dengan memberi pemahaman dan gambaran kelebihan atau manfaat modal sosial berikut:

\section{a. Nilai Pekerjaan Sebagai Nelayan}

Pekerjaan sebagai nelayan yang sudah menjadi kebanggaan sejak nenek moyang mereka di mana Bajo sudah dikenal sabagai masyarakat nelayan yang mempunyai ciri khas yang unik dan menarik di samping keberadaannya yang sangat penting untuk memenuhi kebutuhan ikan bagi masyarakat luas.

Aktivitas nelayan ini juga bisamenjadi asset wisata yang saat dipromosi oleh pemerintah. Perempuan Bajo yang mencari hasil laut menggunakan perahu lepa 
sendirian melaut menggunakan dayung dan layar. Keunikan lain perempuan nelayan Bajo adalah perempuan yang selalu memasarkan atau menjual hasil tangkapnya. Keunikan nelayan Bajo ini bisa menjadi daya tarik tersendiri di samping daya tarik pemandangan laut atau pulau wisata di Kecamatan Soropia.

\section{b. Nilai Tolong Menolong dan Kerja Sama}

Nilai tolong-tolong menolong merupakan salah satu modal sosial yang sangat penting bagi masyarakat nelayan. Nelayan kadang tidak melaut karena berbagai sebab, misal karena sakit, cuaca yang tidak memungkinkan dsb. Dalam keadaan seperti itu biasaya yang tidak melaut diberi ikan oleh tetangga atau kerabat. Begitu juga jika membutuhkan uang tiba-tiba, misal karena sakit, kematian dsb. maka bantuan sangat mereka perlukan. Kebiasaan tolong menolong dalam keadaan tersebut sangat nampak dalam kehidupan mereka.

Kerja sama juga misal jika ada diantara mereka yang mempunyai acara maka secara spontan membantu dengan membagi tugas dan membantu sesuai apa yang dimiliki, seperti tenaga, uang atau materi lainnya.

c. Nilai Trust (Kepercayaan)

Orang Bajo juga mempunyai nilai saling percaya (trust) yang tinggi sebagaimana kita saksikan bahwa rata-rata rumah mereka tidak tertutup pintunya walaupun pemiliknya tak ada dalam rumah, misal karena melaut atau keperluan lain di luar rumah. Mereka percaya bahwa rumah, harta bahkan anak kecilnya aman sekalipun tidak menjaganya sendiri. Tetangga sangat mereka percaya bahkan justru tetangga yang menjaga rumah, harta dan anak-anaknya jika ia tak ada di rumah.

Perempuan sangat dipercaya sehingga perempuan yang selalu menjual hasil tangkap dan perempuan juga yang dipercaya membeli segala keperluan rumah tangga baik yang rutin maupun yang tidak rutin, seperti pembelian perabot atau bahan bangunan rumah.

\section{d. Nilai Kerja Keras dan Rajin Bekerja}

Orang Bajo sudah biasa bekerja tanpa kenal waktu. Kadang mereka, laki-laki maupun perempuan melaut dan menyelam pada malam hari hingga jam 02.00 malam. Sekembali dari melaut, terutama perempuan masih harus mengurus danmenjual hasil tangkap, mencari kayu bakar dan mengangkat air untuk kebutuhan rumah tangga. Mereka juga kadang membuat dan merawat peralatan nelayan.

Mereka rata-rata terbiasa bangun sekitar jam 04.00 subuh untuk mempersiapkan melaut. Beberapa perempuan mengaku hampir tk kenal lelah bekerja demi untuk kebutuhan rumah tangganya.

e. Nilai Keberanian Melaut dan Keterampilan Nelayan

Keberanian melaut yang bahkan dikenal sebagai "manusia air" ini sudah dikenal sejak dahulu. Mereka melaut sampai ke luar negeri dengan menggunakan perahu kayu. Bahkan dahulu mereka melaut bersama istri dan anak-anaknya. Perahu bagaikan rumah mereka. Mereka juga bahkan bisa menyelam selam bebeberapa jam.

Orang Bajo juga bangga dengan kemampuan melaut dan mencari atau menangkap ikan walaupun dengan cara tradisional. Berbagai pengetahuan mereka seperti kemampuan membaca cuaca atau musim, ilmu bintang, pengetahuan tentang tempat-tempat ikan dan sebagainya sebagai sesuatu yang bernilai atau dibaggakan. 


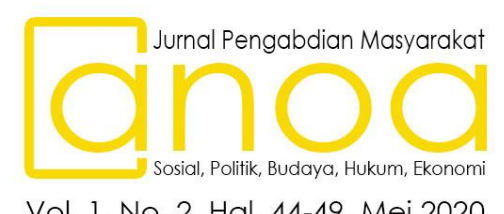

Vol. 1, No. 2, Hal. 44-49, Mei 2020

Semua nilai-nilai sosial yang merupakan modal komunitas ini dalam meraih kebutuhan hidup mereka umumnya warisan leluhur yang perlu diwariskan kepada generasi muda Bajo. Selain karena pekerjaan sebagai nelayan sebagai sumber penghasilan juga budaya maritim yang unik mempunyai daya tarik dalam sector wisata.

\section{Evaluasi}

Setelah dilakukan penyampaian materi bimbingan dalam kelompok besar kemudian dilakukan pendalaman dan diskusi mendalam dalam kelompok kecil. Dalam kegiatan kelompok kecil yang dilakukan tiap dosen pembimbing yang masing-masing menangani empat orang maka diketahui sebagai berikut:

1. Umumnya mereka telah memahami materi yang diberikan dan tujuan kegiatan ini.

2. Mereka menyadari pentingnya modal sosial yang dimiliki.

3. Umumnya mereka siap untuk mewarisi pekerjaan sebagai nelayan. Hanya ada juga yang telah ingin berkiprah ke bidang lain dan telah pernah kuliah hanya berhenti kuliah karena tidak mampu membayar biaya kuliah.

4. Modal sosial lain seperti nilai sosial saling membantu, trust kepercayaan), partisipasi dalam kegiatan, kerja sama, serta etos kerja juga dianggap sesuatu yang positif untuk tetap dipertahankan.

\section{Kesimpulan Dan Saran}

\section{Kesimpulan}

Upaya pelestarian modal sosial generasi muda Bajo berdasarkan diskusi dengan peserta menunjukkan bahwa hampir semua telah menyadari mewarisi modal sosial, seperti kebanggaan untuk menjadi nelayan, trust (saling percaya), saling membantu dan kerja sama serta etos kerja yang selama ini menjadi ciri masyarakat Bajo.

Umumnya mereka bertekad untuk menjaga modal sosial yang disebutkan di atas karena melihat manfaat, baik untuk kesejahteraan keluarganya maupun untuk kepentingan mendukung program wisata dimana budaya Bajo yang unik seperti perempuan nelayan Bajo yang dapat melaut menggunakan perahu lepa sendirian dengan hanya menggunakan dayung dan layar menelusuri laut mencari hasil laut.Keberhasilan kegiatan pelatihan melalui pengenalan parenting bagi keluarga dalam meningkatkan dan mendukung perkembangan fisik, emosional, sosial, finansial, dan intelektual anak pemerintah daerah Di Wilyah Pesisir pantai nirwana di Kelurahan Sulaa, Kecamatan Betoambari, Kota Baubau beserta jajarannya dengan menyiapkan tempat atau ruangan sebagai tempat pelaksanaan kegiatan. Tingginya motivasi para peserta pelatihan dalam mengikuti kegiatan ini, serta kerjasama yang baik dari tim sejak persiapan hingga waktu pelaksanaan juga sukses mendukung keberhasilan pelatihan ini.

\section{Saran}

a. Untuk pelestarian modal sosial oleh generasi Bajo maka pemerintah turut mendukung dengan memberi bantuan sarana dan prasarana serta memperkuat group generasi muda dengan membentuk kelompok-kelompok kecil yang berkiprah kepada pelestarian modal sosial. 
b. Kelompok-kelompok pemuda Bajo ini kemudian dibina atau diberikan penyuluhan dalam bidang penangkapan dan pemeliharaan ikan bahkan juga pengolahan hasil agar bisa mendapatkan hasil yang lebih banyak serta hasil olahan bisa lebih menarik di pasaran.

c. Kelompok-kelompok pemuda nelayan dapat dikompetisikan agar lebih memberi suasana semangat dan lebih menciptakan kreatifitas dalam mencari hasil laut dan pengolahan hasil yang lebih menarik..

\section{DAFTAR PUSTAKA}

Anwar. 2003. "Pengembangan Model Pembelajaran Keterampilan Berbasis Sosial Budaya bagi Perempuan Keluarga Nelayan (Studi Perubahan Sosial Melalui Introduksi Teknologi pada Keluarga Nelayan Tradisional di Kabupaten Kendari)". Bandung: Disertasi Doktor pada PPs Universitas Pendidikan Indonesia.

Baso, Muhammad Nur. 1981. Usaha Kesejahteran Sosial (Social Welfare Service). Diterbitkan oleh Bidang Pendidikan APPS Ujungpandang.

Berger, Peter L dan Thomas Luckmann. 2012. Tafsir Sosial atas Kenyataan: Risalah tentang Sosiologi Pengetahuan. Jakarta: LP3ES.

Hamzah, Awaluddin dan Nurmala K. Panjaitan dan Nuraini W. Prasojo. 2008. Respon Komuhitas Nelayan Terhadap Modernisasi Perikanan (Studi Kasus Nelayan Suku Bajo di Desa Lagasa Kabupaten Muna Sulawesi Tenggara). Sodality: Jurnal Transdisiplin Sosiologi, Komunikasi, dan Ekologi Manusia. Agustus 2008. Vol. 2 N0. 2. p.191-208.

Marhawati. 2010. Gender Dalam Pengelolaan Ekonomi Keluarga Pada Masyarakat Kepulauan Kabupaten Pangkep (Suatu Analisis Gender). Ikfitiyar, 'Vol. 8 No. 2. 2010

Rusli, Muhammad \& Syaifuddin S. Kasim. 2015. Konstruksi sosial peran perempuan nelayan dan kesejahteraan sosial rumah tangga nelayan (studi fenomenologi di pesisir pantai soropia Kabupaten Konawe). Hasil Penelitian Hibah Bersaing. Lembaga Penelitian Unhalu.

Rusli, Muhammad. 2018. Peran Perempuan Nelayan Bajo dan Problematikanya dalam Meraih Kesejahteraan Keluarga (Studi Fenomenologi di Desa Bajo Indah Kec. Soropia Kab. Konawe. PDD Hibah Bersaing Kemenristek.

Saputri, Dini. 2012. Peran Perempuan Nelayan Dalam Produksi Dan Distribusi Hasil Laut. Jurnal Perspektif Sosiologi, Vol. 1 No. 1.

Sugiyono. Perubahan pandangan bekerja masyarakat nelayan Desa Ujungwatu, Jepara (http://www.dkp.go.id/content.php?c=161).

Zacot, Francois-Robert. 2008. Orang Bajo suku Pengembara Laut, Pengalaman Seorang Antropolog. Diterjemahkan oleh Fida Mulyono-Larue \& Ida Budi Pranoto. Jakarta: KPG (Kepustakaan Populer Gramdia).

Zamzami, Lucky. Pemanfaatan Budaya Lokal Terhadap Teknologi Penangkapan Ikan Pada Masyarakat Nelayan (Studi Kasus Di Pasar Laban Kelurahan Bungus Selatan, Kecamatan Bungus Teluk Kabung, Kota Padang) 
